\title{
Cartography of Suicide-Related Health Indicators and Suicide Attempts in Morocco
}

\section{Latifa Amiar}

Faculty of Science and Technology of Tangier,

Abdelmalek Essaadi University

\section{Rachida Soulaymani-Bencheikh}

Poison Control and Pharmacovigilance Center of Morocco, Lamfedel

Cherkaoui Street, Rabat Instituts Rabat (Morocco)

Faculty of Medicine and Pharmacy, Mohammed V University, Av Mohamed

Belarbi El Alaoui, Rabat Institutes, Rabat (Morocco)

\section{Faical El Hattimy}

Hinde Hami

Laboratory of Genetics and Biometry, Project: PPR-B-Mokhtari-FS-UIT

Kenitra.Faculty of Sciences, University Ibn Tofail, Kenitra (Morocco)

\section{Ahmed Aarab}

Faculty of Science and Technology of Tangier,

Abdelmalek Essaadi University

Abderrazak Khadmaoui

Abdelmajid Soulaymani

Laboratory of Genetics and Biometry, Project: PPR-B-Mokhtari-FS-UIT

Kenitra.Faculty of Sciences, University Ibn Tofail, Kenitra (Morocco)

Doi: 10.19044/esj.2018.v14n15p117 URL:http://dx.doi.org/10.19044/esj.2018.v14n15p117

Abstract

The present work consists of a retrospective study of suicidal intoxication during a period stretching from January 1980 to December 2013, reported to the Poison Control and Pharmaco-vigilance Center of Morocco through two systems of data collection: Toxicological Information and Toxico-vigilance. The objective is to determine the spatio-temporal evolution of the incidence, lethality and mortality related to suicides and suicide attempts through intoxication in Morocco. During the study period, the average annual number of suicidal intoxications was 707 cases. All regions of Morocco have been affected but at variable rates. The average age of the victims is $24.39 \pm$ 0.08 years, with a sex ratio of 2.41 in favor of the female sex. In the space of 34 years, the incidence is 2.4 per 100,000 inhabitants, the mortality is 0.67 per million inhabitants and the lethality is $0.08 \%$. The annual increase in 
biological indicators makes suicides and suicide attempts a public health problem, through hospital care and the resulting socio-economic and psychological consequences. This problem seems much more common in urban areas and particularly in the big cities of Morocco.

Keywords: Suicidal poisoning, Incidence, Lethality, Mortality, GIS Data mapping, Morocco

\section{Introduction}

Recently, the Geographic Information System (GIS) is increasingly applied in epidemiology. This system is an excellent way to visualize, manage and analyze epidemiological surveillance data, highlighting trends, interrelationships and interrelationships that remain much more difficult to demonstrate in other ways. However, suicides and suicide attempts have particularly serious consequences for the deliberately intoxicated patient, his family and his entourage. In recent years, morocco has experienced an exponential increase in suicides, although there is no national suicide registry (Barrimi, 2014). this is probably attributed to the evolution of our society, the increase of stress, the distress and socio-economic conditions more and more unfavorable, unemployment, rape and sexual abuse ... etc. It is therefore essential to monitor the spatio-temporal evolution of this behavior, in order to establish an adequate and specific control strategy.

Since 1980, the declaration of all cases of intoxication in Morocco has become mandatory following Ministerial Circular No. 19 829DR / BF / MM. (1980), the MAPPC became the public utility institution mandated by the Ministry of Health responsible for the management of poisoning at the individual and collective level in morocco, it ensures a function of vigilance and health alert.

The present work therefore aims to evaluate health indicators related to the epidemiology of suicidal intoxication in Morocco during the period from 1980 to 2013, with a view to reducing the morbidity and mortality that results, in the various administrative regions of Morocco.

\section{Patients and methods}

The system of sanitary vigilance undertaken by the Moroccan AntiPoison and Pharmacovigilance Center (MAPPC) is based on the collection, management, analysis and interpretation of declarations of poisoning cases. This system relies on the systematic and centralized collection of data from the victims' files declared to the MAPPC by mail received from the various medical delegations throughout the Moroccan territory (toxicovigilance system) and a system based on the medical records completed by the doctor on call for every call to the Toxicological Information of MAPPC 
(Toxicological Information). This system is used to deliver toxicology information 24 hours a day, 7 days a week (telephone response). Each statement is the subject of a creation of a medical file in which are designated all the information relating to the call, the source, the patient, the suspected toxic and intoxication.

Records and medical records undergo treatment in three important steps:

- The preliminary analysis (sorting, numbering, classification and coding according to the thesaurus adopted by the MAPPC).

- data entry on a computer medium allowing the development of a database

- Secure archiving of data to establish action plans that can reduce morbidity and mortality.

- This information is part of the epidemiological investigation and will be helpful in understanding the problem in order to design an action plan and establish a control strategy. The temporal and spatial analysis of the incidence, lethality and mortality of suicide-related intoxications and suicides is carried out by analyzing the data collected. These different basic indicators are :

$$
\begin{aligned}
& \underline{\text { Incidence }}=\quad \frac{\text { Notified cases } \times 100,000}{\text { covered population }} \\
& \text { Mortality }=\quad \frac{\text { Notified deaths } \times 100,000}{\text { covered population }} \\
& \text { Case Fatality Rate }=\frac{\text { Notified deaths } \times 100}{\text { Notified cases }}
\end{aligned}
$$

The population used is based on the 2004 census, overhead projections and population projections, and the 2009-2010 National Population Demographic Survey prepared by the Office of the High Commissioner for Planning of Morocco (Haut-Commissariat au Plan du Maroc, 2009)

The manipulation, the processing of geographic data and the production of thematic maps of the distribution of incidence, lethality and global mortality were carried out thanks to the Geographical Information System.

\section{Results and discussion}

The demographic explosion, in several regions of Morocco, the important evolution of the behavior "stress", the difficult conditions of the current life and the social injustice, represent major risk factors to the voluntary suicidal intoxications.

The figure below shows the temporal evolution of suicides according to the years of the studied period. the results of this analysis show that the 
tendency to report suicide attempts is increasing, with a coefficient of determination of 0.80 . however, the maximum values are displayed during the years 2003, 2012 and 2013, with a frequency that exceeds 1400 declarations.

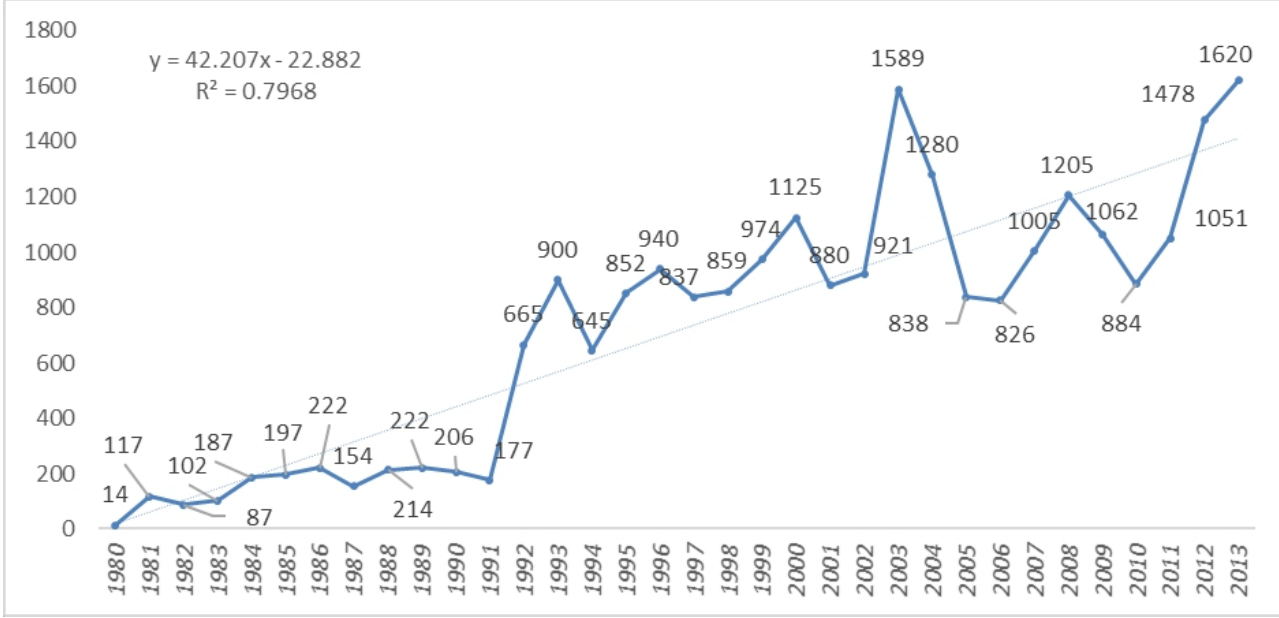

Figure 1: Evolution of the number of suicides and suicide attempts per year from 1980 to 2013.

The following table shows the distribution of suicide attempts by region during the study period. In addition, 8782 suicide attempts are recorded during this period. The maximum number of declarations is displayed in the regions of Greater Casablanca and Rabat Salé Zemmour Zaer, with a percentage approaching 15\%, followed by the Eastern region with a percentage of $10.5 \%$.

Table I: Overall distribution of suicides and attempted suicide by intoxication during the study period.

\begin{tabular}{lllllll}
\hline Regions & Unspecified & Death & Healing & N cases & $\begin{array}{l}\text { Incidence } \\
(100000 \text { inh })\end{array}$ & Mortality (1 million inh) \\
\hline Chaouia-Ouardigha & 765 & 56 & 531 & 1352 & 81,74 & 33,86 \\
Doukala-Abda & 196 & 44 & 690 & 930 & 46,90 & 22,19 \\
Fes-Boulemane & 184 & 18 & 576 & 778 & 49,55 & 11,46 \\
Gharb-Chrarda-Beni Hssen & 290 & 40 & 616 & 946 & 50,94 & 21,54 \\
Grand Casablanca & 1753 & 59 & 1935 & 3747 & 103,45 & 16,29 \\
Guelmim-Es Semara & 95 & 7 & 168 & 270 & 58,82 & 15,25 \\
Laayoune-Boujdour-Sakia El Hamra & 66 & 6 & 124 & 196 & 76,86 & 23,53 \\
Marrakech-Tensift-Al Haouz & 1166 & 25 & 818 & 2009 & 64,83 & 8,07 \\
Meknès-Tafilalt & 448 & 63 & 1533 & 2044 & 95,51 & 29,44 \\
Oued Ed-Dahab-Lagouira & 3 & 0 & 6 & 9 & 6,94 & 0,00 \\
Rabat-Sale-Zemmour-Zaer & 901 & 82 & 2606 & 3589 & 152,08 & 34,75 \\
L'Oriental & 957 & 68 & 1482 & 2507 & 130,91 & 35,51 \\
Souss-Massa-Daraa & 252 & 92 & 1040 & 1384 & 44,56 & 29,62 \\
Tadla-Azilal & 902 & 60 & 1295 & 2257 & 155,76 & 41,41 \\
Tanger-Tétouan & 656 & 24 & 921 & 1601 & 64,95 & 9,74 \\
Taza-Al Hoceima Taounate & 148 & 31 & 240 & 419 & 23,19 & 17,16 \\
\hline Total & 8782 & 675 & 14581 & 24038 & 80,47 & 2,57 \\
\hline
\end{tabular}


Figure 2 summarizes the distribution of the declarations of the suicide attempts according to the regions of the kingdom.

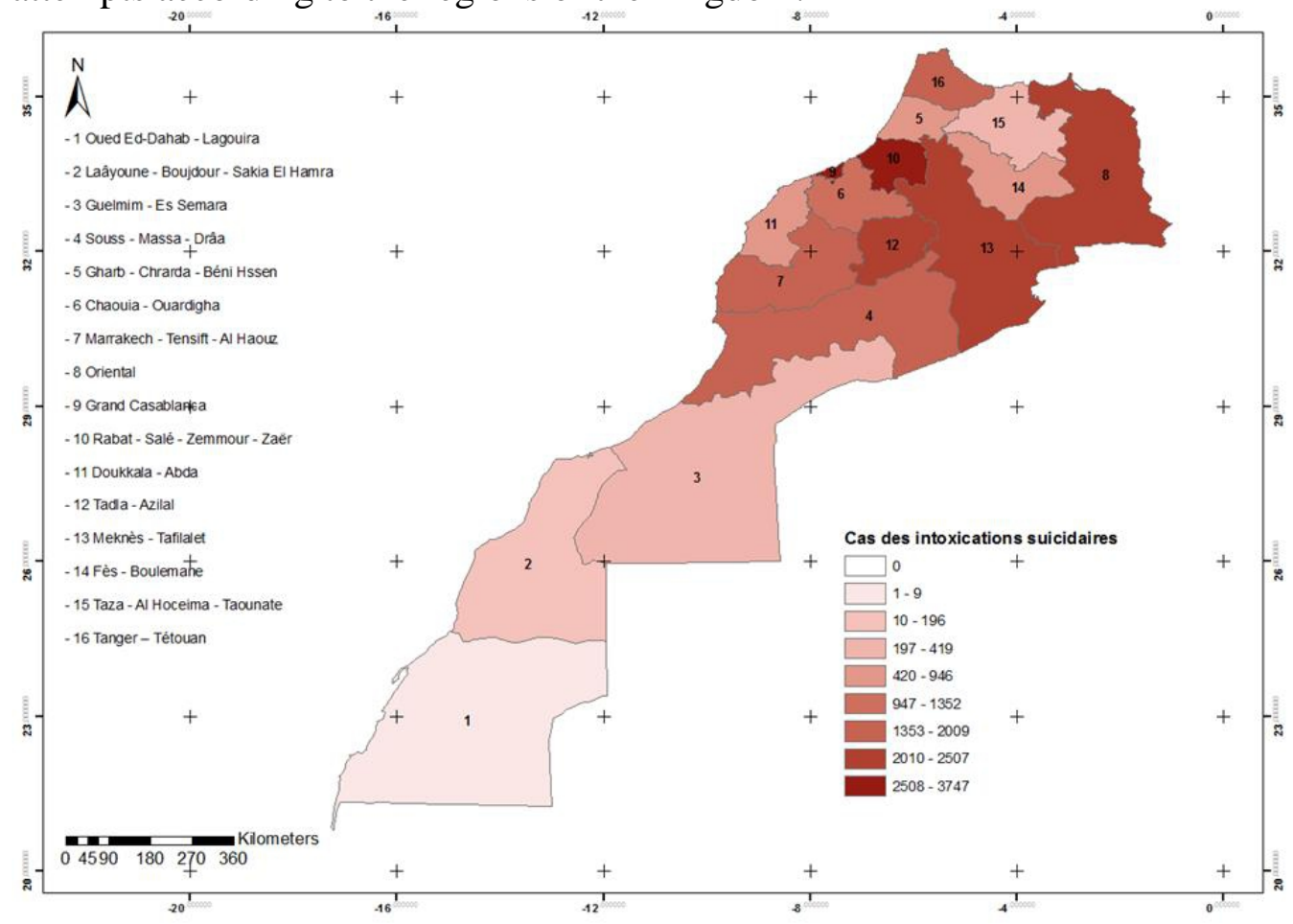

Figure 2: Distribution of suicide attempt cases from 1980 to 2013 by region

Figure 3 represents the geographical distribution of the incidence of attempted suicide from 1980 to 2013. This analysis shows that the average incidence of suicide attempts is 80 cases per 100000 inhabitants. In fact, the Tadla Azilal and Rabat salé Zemmour Zaer regions occupy the first position with an incidence of around 150 cases per 100,000 inhabitants. 100,000 inhabitants followed the Eastern region with 131 cases per 100,000 inhabitants. In addition, the Greater Casablanca region is in fourth position despite the large number of declarations (Figure 3). 


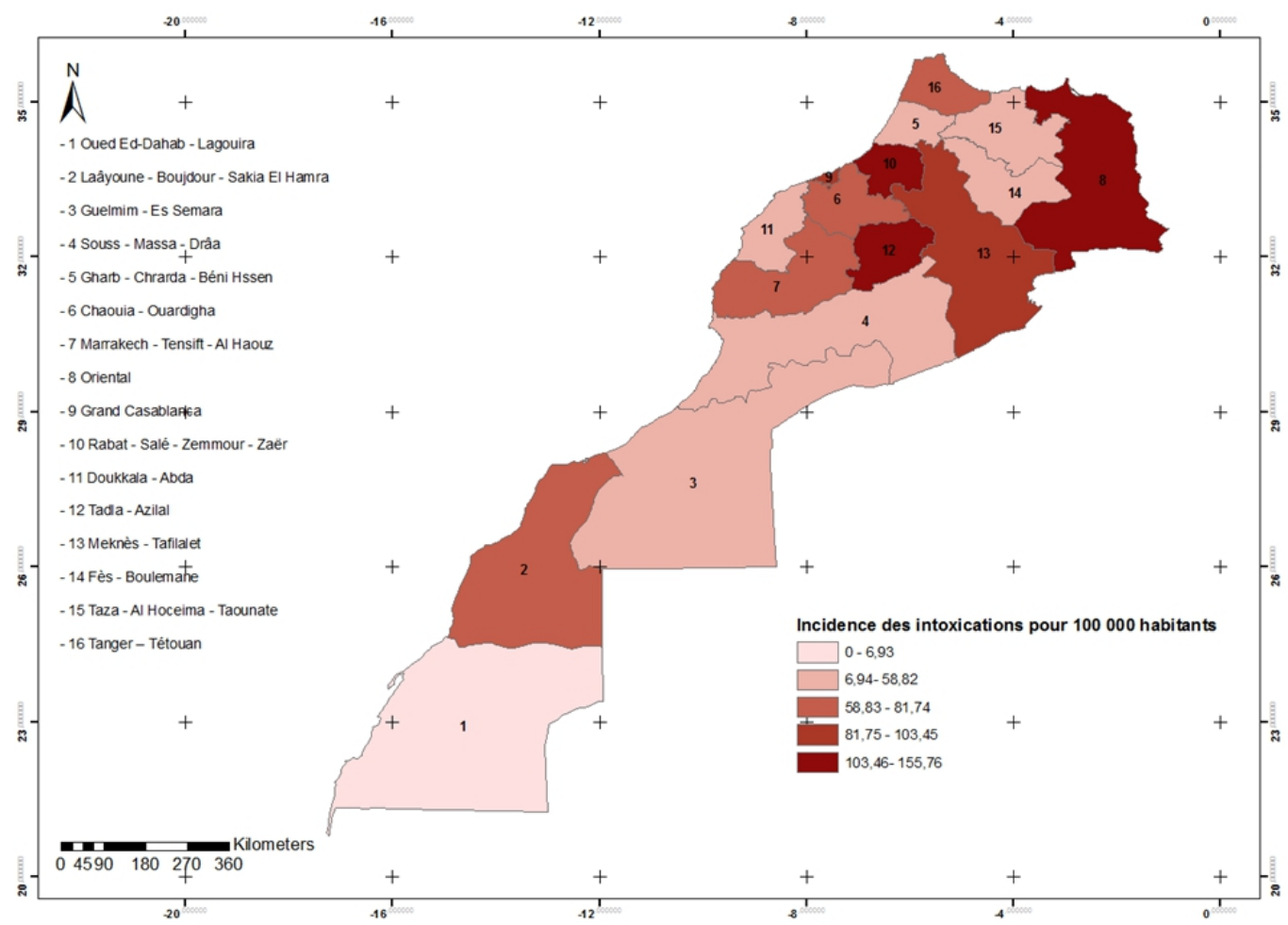

Figure 3: Distribution of the incidence of suicide attempts between 1980 and 2013 by region.

Figure 4 shows the results of the number of sequelae per region. Suicide attempts often create various sequels. In our sample, $4.5 \%$ of cases had sequelae $(\mathrm{n}=411)$. According to figure $(2)$, all regions have reported sequelae cases, with a maximum (155 cases) reported in the Rabat Salé Zemmour Zaier region, representing a rate of $4 \%$. 


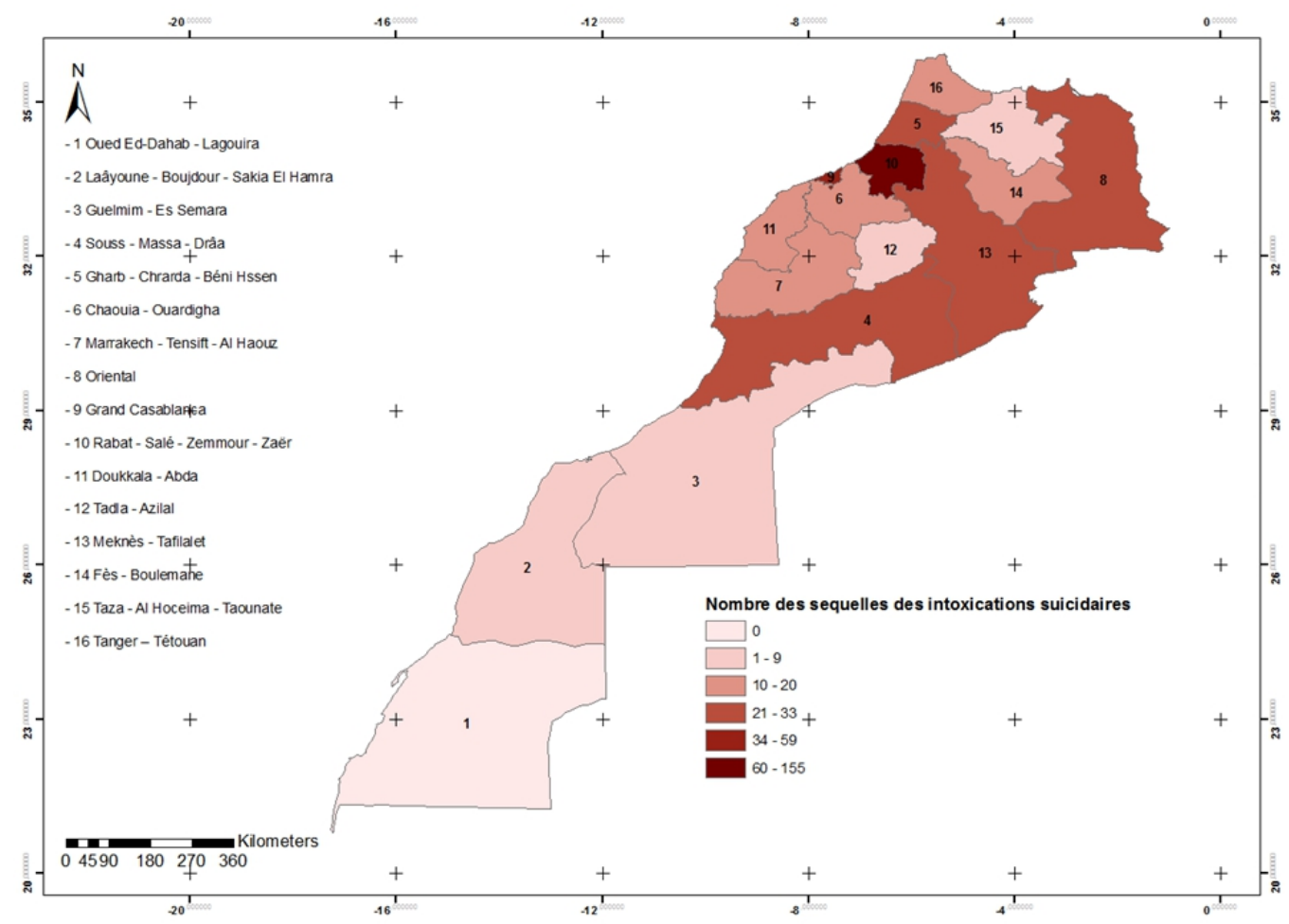

Figure 4: Distribution of the number of sequelae following a suicide attempt by region between 1980 and 2013.

Figures 5 and 6 show respectively lethality and mortality by region. During the 34 years of study, 675 deaths were reported, this corresponds to a lethality of $2.81 \%$ and a mortality of 22.6 deaths per 100000 inhabitants (table). However, the Souss Massa Draa region has the highest number of deaths (92 cases). the maximum of letality is recorded in the region of Taza Al Hoceima Taounate (6.6\%) (Figure 5). About mortality, the Tadla azilal region had 41 deaths per 100,000 inhabitants, followed by the eastern region and Rabat Salé Zemmour region with about 35 deaths per 100,000 inhabitants (Figure 6). 


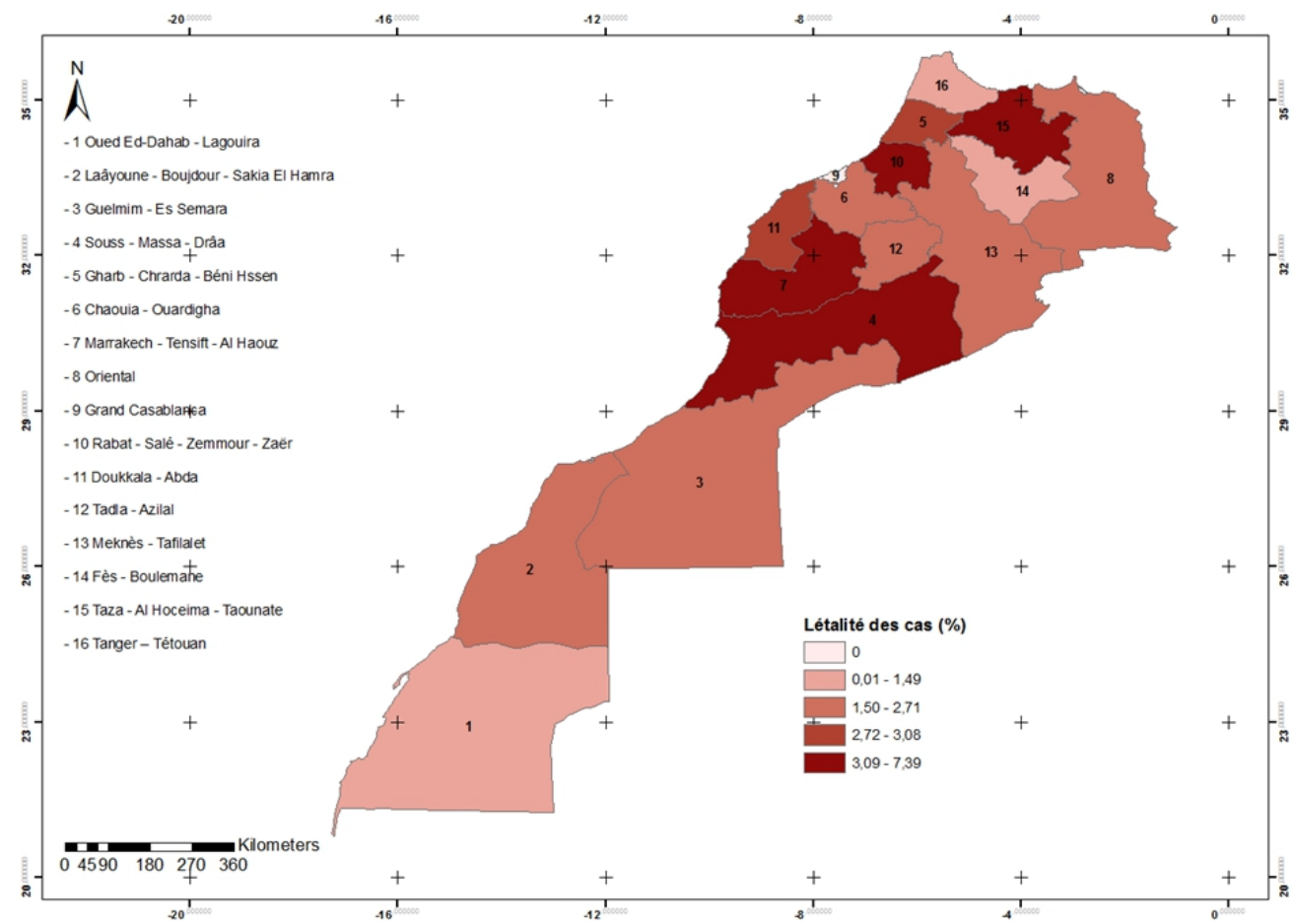

Figure 5: Lethality of suicides by region between 1980 and 2013.

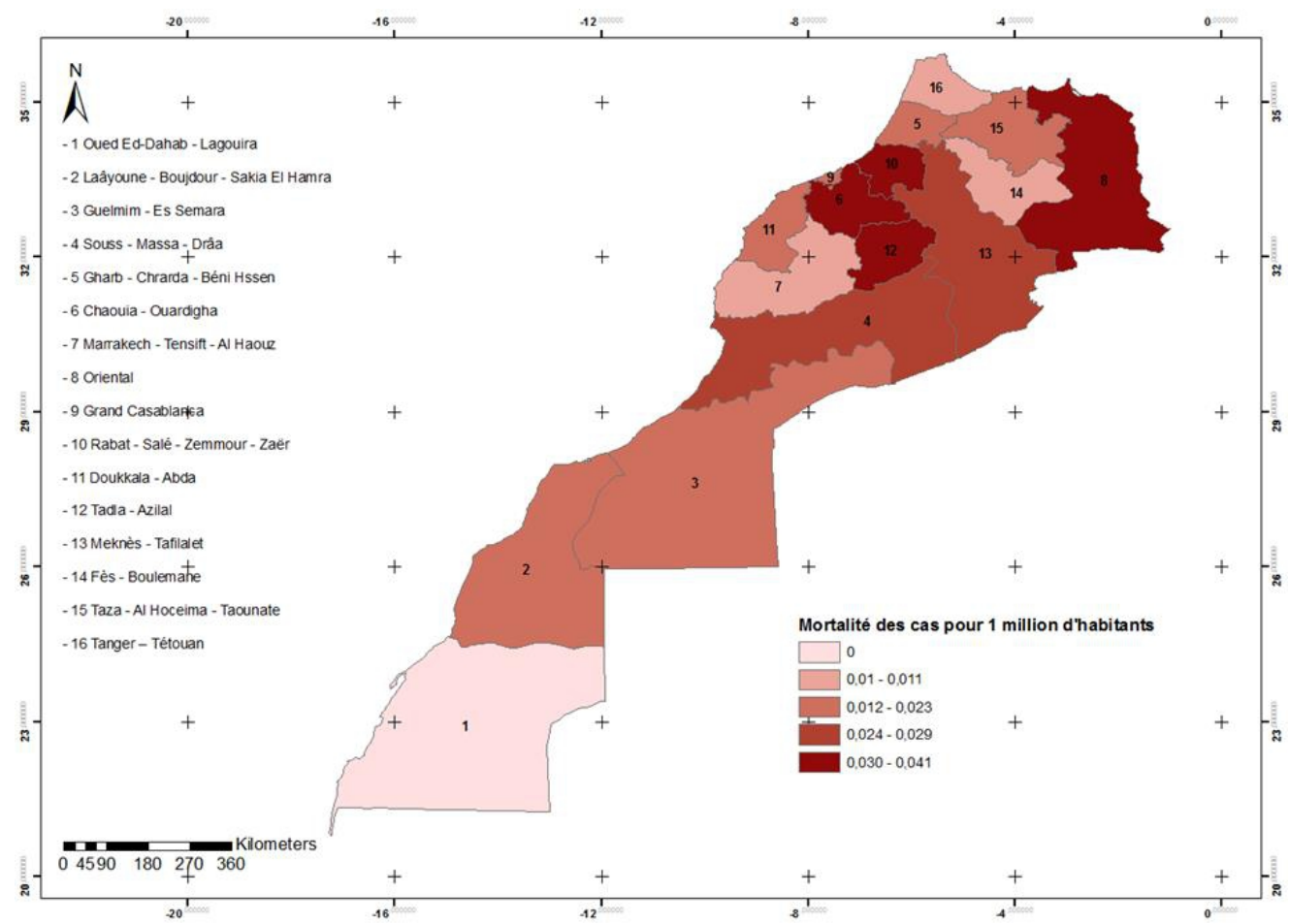

Figure 6: Mortality of suicide attempts by region between 1980 and 2013. 


\section{Discussion}

In Morocco, suicide attempts currently represent a real public health problem as well as a frequent reason for admission to emergency and medical resuscitation (Hami, 2009; Echahbi, 2011 ; Achour, 2011), even if they are a taboo subject, difficult to address and perceived as a shame for the families affected (Bernard, 2014).

Suicide attempts represent $24.5 \%$ of all cases of acute poisoning collected at the MAPPC except scorpion poisoning (Ouammi, 2009). With an annual incidence rate of 2.4 cases per 100,000 populations, this rate remains relatively low compared to another neighboring country, such as France, which recorded a rate of 17.8 per 100,000 inhabitants in 2002 (Chappert, 2003).

The geographical distribution of cases of suicide attempts made it possible to place the regions of Greater Casablanca, Rabat-Sale-ZemmourZaer and the Eastern region in first position. this situation may be explained by the high rate of urbanization in these regions. This is consistent with the results reported by the High Commission to the plan, which confirms that the number of urban suicide attempts is 7 times higher than in rural areas (Amiar, 2016). These three regions still occupy the first positions in the incidence of suicide attempts (Mahir, 2013; Diallo, 2013).

During the study period, suicide attempts resulted in 675 deaths, with a lethality of about $3 \%$. this lethality is explained by the choice of the manner of suicide which generally remains self-poisoning. This technique according to Platt in 1988 is classified as the least frequent (Platt, 1988). the Taza AlHoceima Taounate region recorded the highest case fatality rate with a percentage of $7.4 \%$. This can be explained by the low rate of reporting since the rate of urbanization does not exceed $27 \%$ according to the High Commission for Planning.

\section{Conclusion}

Despite the efforts undertaken by the sector, the problem still remains especially in the urban environment where risk factors are numerous. The reduction of the suicide rate in Morocco represents a challenge and a record to beat, but this in collaboration of all the instances.

\section{References:}

1. Barrimi M., Zaidi K. Hlal H. Kettani N., Khelafa S., Rammouz I., Aalouane R., Tentatives de suicides violentes à l'hôpital général de Fès (Maroc) : évaluation et prise en charge en psychiatrie de liaison. Étude prospective sur six mois. L'Évolution Psychiatrique, (Vol 79), 4 : 2014, 619-628

2. Haut-Commissariat au Plan du Maroc (C) 2009 Centre National de 
Documentation www.hcp.ma/Demographie-population.

3. Hami H., Soulaymani A., Ouammi L., Rhalem N., Mokhtari A. et Soulaymani R. Tentatives de suicide au Maroc. Abstract. Revue d'épidémiologie et Santé Publique ; 57 (Sup.) S29-S29.

4. Echahbi N., Hami H., Ouammi L., Soulaymani A., Mokhtari A., Benazzouz B., et Soulaymani R. Paraphénylène diamine et suicide dans la region de Marrakech-Tensift- El-Haouz au Maroc. L'Encéphale 37 (Sup. 1) 3 - 207, January 2011.

5. Achour S., Khattabi A., Rhalem N., Ouammi L., Mokhtari A., Soulaymani A. et Soulaymani R. L'intoxication par les pesticides chez l'enfant au Maroc : profil épidémiologique et aspects pronostiques (1990-2008). Santé Publique 2011. N³ (Vol. 23) 195-205.

6. J.-C.Bernard. Épidémiologie et représentations du suicide en Afrique sub-saharienne. European Psychiatry, 2014 (Vol 29) ; 8 : 641.

7. Ouammi L., Rhalem N., Aghandouz R., Semlali I., Jalal G., Benlarabi S., Mokhtari A., Soulaymani A. et Soulaymani R. Profile épidémiologique des intoxications au Maroc de 1980 à 2007. Toxicologie Maroc. $\mathrm{N}^{\circ} 1$, Mai 2009. 8-13.

8. Chappert J.-L., Pequignot F., Pavillon G., Jougla E., 2003, « Évaluation de la qualité des données de mortalité par suicide : biais et impact sur les données nationales en France, à partir des causes indéterminées quant à l'intention », CépiDc Inserm, Document de travail, Série Études, ${ }^{\circ} 30$, avril, Drees.

9. AMIAR L., AARAB A., MOKHTARI A., SOULAYMANI R.Aspects Épidémiologiques des Suicides et des Tentatives de Suicide par Intoxication au Maroc. European Journal of Scientific Research, Vol. 140 No 3 July, 2016, pp.282-293.

10. Mahir S., Soulaymani A., Hami H., Mokhtari A., Benali D., Ouammi L., Windy M. et Soulaymani R. Suicides par intoxication dans la région de Souss-Massa-Drâa au Maroc. Santé publique volume 25. N³ - mai-juin 2013. 343-350.

11. Diallo T., Hami H., Maiga A., CoulibalyB., Maiga D., Mokhtari A., Soulaymani R. et Soulaymani A. Introduction Épidémiologie et facteurs de risque des intoxications volontaires au Mali. Santé Publique. Volume 25. N³. Mai-juin 2013359 - 366.

12. Plat S., Backett S., Kreitman N. Social construction or causal ascription: distinguishing suicide from undetermined deaths. Soc Psychiatry Psychiatr Epidemiol, 1988; 23: 217-21. 